\title{
Häckningsmiljöns betydelse för häckningsframgången hos havsfiskande smålom Gavia stellata i Västerbotten
}

\author{
ULF SKYLLBERG, JOAKIM LESSMANN \& PER HANSSON
}

\begin{abstract}
In Sweden sea-foraging Red-throated Divers are found only in the north-eastern part, along the Gulf of Bothnia and the Bothian Bay. The breeding biology of these possibly 100-200 pairs is virtually unknown. In this study, the breeding success of 15 pairs of these birds was related to lake and nesting site characteristics. During the years 1993-1998, a total of 53 initiated incubations were recorded in 14 different lakes within a $400 \mathrm{~km}^{2}$ area. Out of a total of 43 well-grown young ( 28 incubations) all except 5 (3 incubations) were with certainty hatched in nests located on small islets or on floating Spaghnum spp. moss mats. The overall breeding success, expressed as non-fledged, half-grown chicks (large young) per incubation, was 0.81 . The breeding success was significantly lower $(0.01<\mathrm{p}<0.05$, Kruskal-Wallis followed by Dunn's test) in bog-type mire lakes ( 0.33 young per incubation) than in lakes with a mosaic character of open water, high-grown Carex vegetation and Spaghnum moss mats (0.94 young per incubation). Also in forest lakes, formed in depressions of glacial
\end{abstract}

till, the production was higher than in mire lakes (1.09 young per incubation). It was found that a dense cover of high vegetation close to the nest was the most important factor for the breeding success $\left(p<0.01\right.$, Spearmans $\left.r_{s}\right)$, whereas distance between the nest and the shore showed a weak statistical significance $(0.05<\mathrm{p}<0.10)$. On a lake level scale, it was found that breeding success increased with decreasing percentage open water (i.e. increasing mosaic character, $\mathrm{p}<0.01$, Spearmans $r_{\mathrm{s}}$ ) whereas the absolute size of the lake ( 0.26 to 15.9 ha), maximum distance over open water and distance to the sea $(0.3$ to $4.0 \mathrm{~km})$ did not seem to affect the breeding success. The influence of predation and yearly fluctuations in lake water level on breeding success are discussed.

Ulf Skyllberg, Brännavägen 38, S-907 88 Täfteå, Sweden. Joakim Lessmann, Fältgatan 10, S-903 36 Umeå, Sweden. Per Hansson, Ferievägen 66, S-918 32 Sävar, Sweden.

Received 11 April 1997, Withdrawn for addition of new data; resubmitted 9 August 1999, Accepted 16 August 1999 , Editors: M. Hake \& S. Svensson

\section{Inledning}

Enöverväldigande majoritet av Sveriges 1200-1400 par smålom (Eriksson \& Lindberg 1999) häckar i små myr- och skogstjärnar och fiskar i närbelägna större sötvatten. Detta är t.ex. fallet för de ca 15-20 par i sydvästra Sverige, som studerats ingående under 1980-talet (Eriksson 1994), och de drygt 50 par som årligen följts i Malungstrakten (Dahlén 1996). Beståndet i sydvästra Sverige visade indikationer på en vikande trend under perioden 19601985, men tycks därefter återhämtat sig något (Eriksson \& Johansson 1997). Orsakerna till minskningen är oklara, men förändringar av häckningssjöarna efter dikningsingrepp och påverkan av luftföroreningar kan ha haft betydelse (Eriksson m.fl. 1988).
Kunskapen om långsiktiga beståndstrender och häckningsutfall för smålommar häckande i norra Sverige är liten. Projekt LOM, som sedan 1994 drivs gemensamt av Naturskyddsföreningen och Sveriges Ornitologiska Förening, kan delvis ge svar på dessa frågeställningar (Eriksson \& Lindberg 1999), medan mer specifika studier krävs för att vi skall få bättre kunskap om vilka faktorer som styr smålommens häckningsframgång.

Betydande delar av världens smålommar häckar, i motsats till de svenska, i marin miljö. Havsfiskande populationer har t.ex. studerats på Shetlandsöarna (Gomersall 1986), Orkneyöarna (Booth 1982) och i Kanada (Douglas \& Reimchen 1988, Eberl \& Picman 1993). I Sverige finns havsfiskande smålom- 
mar längs norrlandskusten. Av dessa hyser Holmöarkipelagen och angränsande fastlandsdel inom Umeå kommun ca 35-40 par smålom(Olsson 1992). Mycket lite är känt och dokumenterat om dessa lommars häckningsbiologi och häckningsframgång. Syftet med föreliggande studie är dels att dokumentera häckningsframgången hos ca 15 par av de kustfiskande smålommar, som häckar i Västerbottens södra kustland, dels att identifiera betydelsefulla faktorer bakom häckningsutfallet.

\section{Studieområde och inventeringsmetodik}

\section{Studieområdets storskaliga topografi, geologi och vegetation}

Våra studier bedrevs inom ett ca $400 \mathrm{~km}^{2}$ stort område begränsat av Umeälven och väg E4 i väster, Västra Kvarken i öster och Dalkarlså i norr (Figur 1). Områdets topografi är flack och präglas av en nordsydgående relief vilken i den mindre skalan består av olika typer av moränformationer (t.ex. drumliner) och i den större skalan av mer markerade dalgångar.

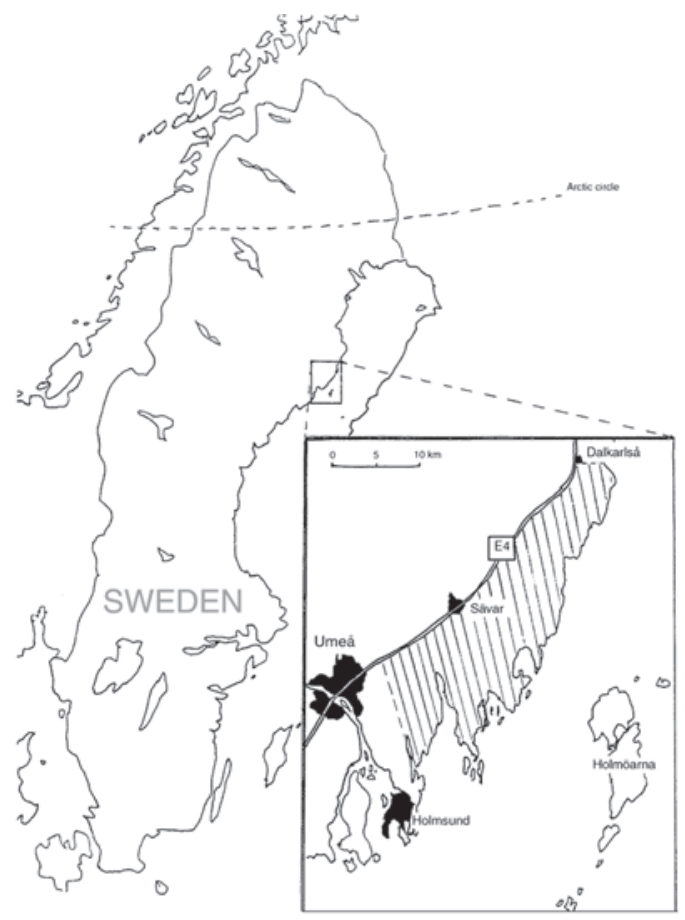

Figur 1. Inventeringsområdet.

The study area.
Den flacka topografin resulterar i en generellt högt liggande grundvattenyta som ger gynnsamma förutsättningar för torvbildning. Sammanhängande myrområden dominerar alltmer landskapet med ökat avstånd från kusten. Landhöjningen är för närvarande omkring $0.9 \mathrm{~m}$. per hundra år, vilket i kombination med den flacka terrängen kontinuerligt skapar nya kustnära sjöar samtidigt som äldre sjöar successivt växer igen.

Bergarterna i undersökningsområdet domineras av s.k. kustgnejser, som är fattiga på näringsämnen som kalcium, magnesium och kalium. Därför är de flesta myrmarker och sjöar i området tämligen näringsfattiga. Myrarna är uppbyggda av vitmossearter Sphagnum spp. och har övervägande karaktär av fattigkärr (Sjörs 1956). Även de minerogent påverkade sjöarnas strandzon är bitvis avgränsade mot fastmarken av en bård av fattigkärr, vilken ofta domineras av vitmossor. I många sjöar finns mer eller mindre fast förankrade eller flytande "mattor" av vitmossa på vilka högre vegetation efter en tid kan få fäste. Fältskiktet på myrarna domineras av arter som rosling Andromeda polifolia, tranbär Vaccinium oxycoccus, skvattram Ledum palustre och ljung Calluna vulgaris. Vegetationen i mer näringsfattiga strandzoner domineras av tuvull Eriophorum vaginatum, dystarr Carex limosa, gråstarr C. curta, kråkklöver Comarum palustre och vattenklöver Menyanthes trifoliata, medan högvuxna arter som flaskstarr $C$. rostrata, trådstarr C. lasiocarpa och sjöfräken Equisetum fluviatile dominerar strandzonen i de något mer näringsrika sjöarna. Det skogsbildande trädslaget är huvudsakligen gran Picea abies. Tall Pinus sylvestris finns endast i form av glesa bestånd av martallar i gränszonen mellan myr- och fastmark. Vid några sjöar finns tallungskog som planterats på tidigare granskogsklädd mark. Lövträdsinslaget domineras av glasbjörk Betula pubescens, som tillsammans med rönn Sorbus aucuparia även dominerar på yngre hyggen. Gråal Alnus incana återfinns ofta som en bård längs strandkanten på yngre sjöar nära kusten.

\section{Klassificering av häckningssjöar}

I syfte att hitta ett samband mellan häckningsresultat och häckningsmiljö har vi klassificerat samtliga sjöar som hyst stationära par eller häckande lommar i tre olika typer: (typ 1) myrgöl, (typ 2) skogstjärn och (typ 3) sjöar bestående av en mosaik av öppen vattenyta, delvis gungflyartade vitmossemattor och ruggar av mer näringskrävande vegetation som t.ex. starr Carex spp. och säv Scirpus spp. 


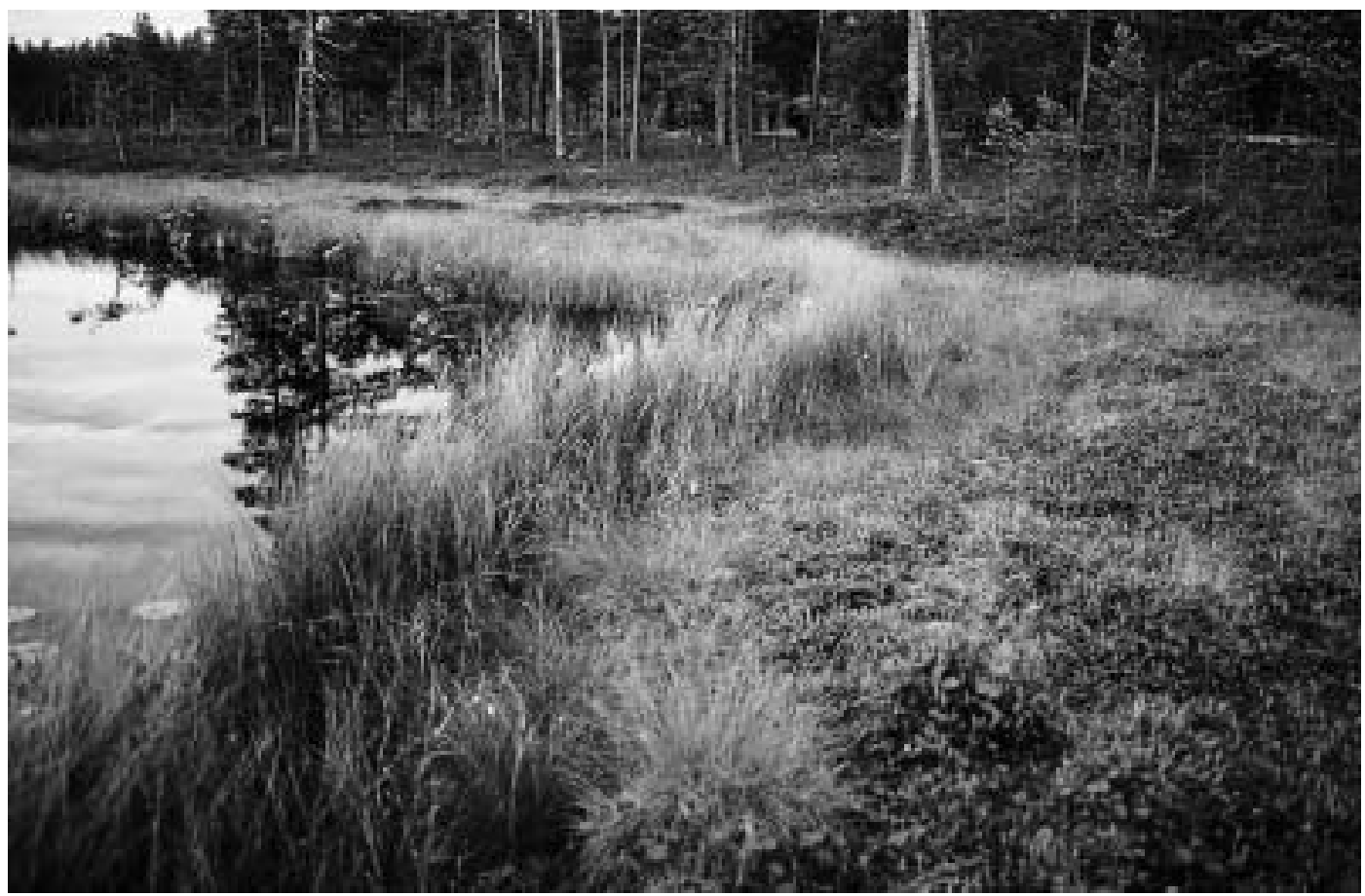

Figur 2. Myrgöl där vitmossemattan är bevuxen med trådstarr Carex lasiocarpa i strandlinjen. Sjö nummer 10.

Mire lake with some Carex lasiocarpa on the shore. Lake no. 10.

Myrgölen (Sjörs, 1956) är det djupaste partiet i en tidigare större sjö som med tiden ackumulerat organiskt sediment och successivt vuxit igen. Den karakteriseras i sitt typfall av en sammanhängande klarvattenyta utan inslag av ruggar av högre vegetation och har en väldefinierad strandkontur bestående av vitmossemattor. Eventuellt inslag av mer högvuxen vegetation längs stränderna beror av näringstillskott i tillrinnande vatten. Är inslaget av vatten från omkringliggande minerogen fastmark litet saknas i det närmaste högvuxna starrarter, medan betydande starrpartier kan förekomma där myrgölen tillförs näringsrikt vatten (Figur 2). Myrgölarna i området är generellt näringsfattiga (dystrofa).

Skogstjärnar (Figur 3a) är bildade i sänkor i moräntäcket, ofta belägna mellan två moränryggar av drumlintyp. Dessa sjöar tillförs i hög grad minerogent markvatten från omkringliggande terräng, men den näringsfattiga berggrunden ger ändå sjöarna en oligotrof karaktär. Normalt är sjöarna omgivna av äldre barrskog och har en strandzon bestående av vitmossemattor blandade med starrpartier. Utanför stranden finns ofta en bård av starr- och sävbälten av varierande täthet och utsträckning (Figur 3b). I någ- ra fall är sjöarna omgivna av hyggen eller ungskog, vilket har resulterat $i$ ett tillskott av näring och ljus som tillfälligtvis förändrar vegetationssammansättningen såväl längs sjöns stränder som i själva sjön.

De sjöar som uppvisar en blandning av sjö, kärroch mossepartier benämner vi mosaik (Figur 4). De utgör de mest näringsrika sjöarna i området och är i flera fall sannolikt en produkt av dikningsingrepp. I dessa sjöar finns ofta grupper av döda träd, vilket indikerar att vatten tillförts från ett uppströms beläget dikningsobjekt. Näring tillförs med dikningsvattnet, vilket medför att vegetationens sammansättning förändras till en rikare typ där både högstarr- och vitmossepartier blandas. Generellt kan en mer mosaikartad karaktär av högre vegetation och klarvattenytor förväntas då en näringsfattig sjö fått en förhöjd näringsstatus, medan en alltför hög näringstillförsel (i kombination med dränering) resulterar i betydande igenväxning och en minskad grad av mosaik.

Sjöarnas totala yta, inklusive flytande och bottenförankrad vegetation, mättes på det ekonomiska kartbladet (upprättat efter flygfotografering 1982), medan öppen klarvattenyta och största avstånd över 


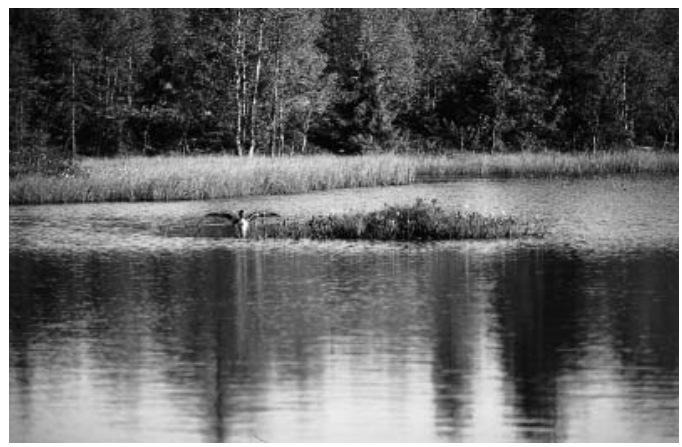

Figur 3a. Typisk skogstjärn med boholme. Sjö nummer 6 . Typical forest lake and islet with nest. Lake no. 6.

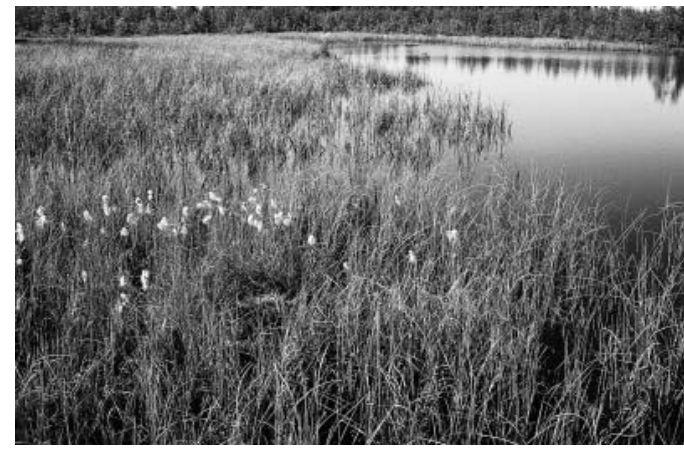

Figur 3b. Vegetationsrik skogsstjärn. Bobalen återfinns i det tätaste partiet av trådstarr Carex lasiocarpa. Sjö nummer 9. Vegetation-rich forest lake. The nest is located in the dense Carex lasiocarpa vegetation. Lake no. 9.

av häckningar mellan sjöar betydligt sämre och besökskategorierna i), ii) och iii) kom att löpa parallellt över tiden. Under 1998 var inventeringsintensiteten sämre i sjöar som under 1993-1997 inte visat sig hysa häckande lommar, varför antalet stationära, ej häckande, par inte redovisas för säsongen 1998.

Sjöarna inventerades med handkikare från land. Närvaro av stationärt par vid minst två tillfällen antas indikera ett revir inom vilket häckningsförsök inte kan uteslutas. Häckning likställer vi med iakttagande av ruvande fågel. I sjö nummer 2 (Tabell 1) kunde boplatsen inte lokaliseras p.g.a. kraftigt utvecklad vegetation och därför konstaterades häckning först i och med att ungar iakttogs. Eftersom vi i denna sjö kan ha missat ett okänt antal avbrutna häckningar är den ej medtagen i den statistiska analysen. Tidpunkten för äggläggning skattades utifrån besök före och efter första tillfället med iakttagen ruvning, samt en kontroll av denna tidpunkt genom att subtrahera summan av ungarnas skattade ålder och 30 dagars ruvningstid (Bundy 1976) från det datum då ungarna visade sig för första gången. Avbruten häckning fastställdes då ett tidigare iakttaget ruvande par vid ett senare tillfälle visat sig ha övergivit boet och/eller lämnat häckningssjön. Att så var fallet kontrollerades vid ytterligare minst ett tillfälle. Predation av ägg eller av nykläckta ungar kunde inte särskiljas. I enlighet med metodiken inom Projekt LOM (Eriksson \& Lindberg 1999) baseras häckningsresultatet på summan av antalet ungar med övervägande juvenil fjäderdräkt och en storlek uppgående till minst hälften av de vuxna fåglarnas (kallas hädanefter "stora ungar"). I fall av konstaterad omläggning efter misslyckad häckning, är endast den omlagda kullen medtagen i statistiken 


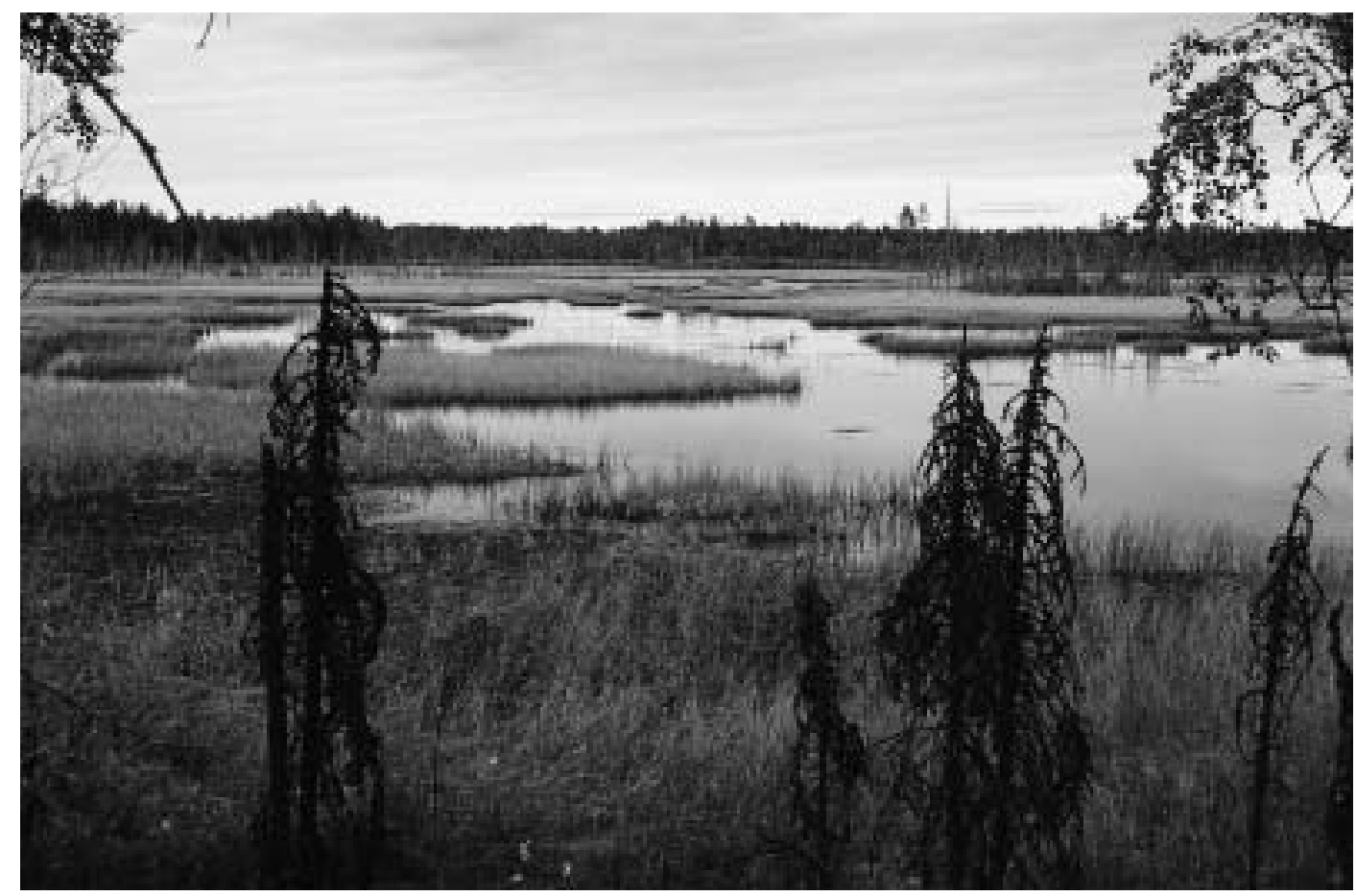

Figur 4. Mosaik av öppet vatten, gungflyn av vitmossemattor och ruggar av starr och säv. Sjö nummer 1.

Lake classified as a mosaik of open water, floating Sphagnum spp. mats and more nutrient demanding vegetations such as Carex spp. and Scirpus spp. Lake no. 1.

(d.v.s. det första misslyckade försöket bortses ifrån). Detta anser vi vara det mest korrekta tillvägagångssättet eftersom misslyckanden efter endast en mycket kort tids ruvning lätt förbises med den inventeringsintensitet vi använt oss av.

Efter det att ungarna lämnat häckningssjön (augusti-september) besöktes samtliga boplatser (i ett fall brukades kanot) och vegetationens medelhöjd och täckningsgrad mättes inom $0,5 \mathrm{~m}$ från bobalens ytterkanter. Med måttband mättes avståndet från boplatsens (bobale eller mindre boholme där sådan brukades) ytterkanter till den närmaste, med fastmark sammanhängande, gungfly eller annan tät, delvis bärande vegetation (hädanefter benämnd gungfly), samt mellan boplatsen och sammanhängande fastmark. Med fastmark menas mark som är stabil nog att bära en normalbyggd person (iklädd stövlar).

\section{Resultat och diskussion}

Vattenståndsfluktuationer och häckningssäsongens tidsmässiga utsträckning

Smålommar observerades i häckningssjöarna från det att isen bröt upp, ofta första till andra veckan i maj, till och med slutet av september. Beräknad tidpunkt för äggläggning, avrundad till närmaste femdagarsperiod, varierade från omkring 20 maj till 10 juli. Sannolikt var det framförallt vattenståndets nivå i sjöarna som styrde denna tidpunkt. Baserat på en ungefärlig beräknad tidpunkt för kläckning och en genomsnittlig ungvårdnadstid om 45 dagar (Bundy 1976) kom häckningssäsongen, definierad som den tid då vuxna fåglar eller ungfåglar vistas i häcksjöarna, att sträcka sig från omkring 10 maj till omkring 30 augusti ett år med intermediärt vattenstånd (1994), medan den sista flygga ungen beräknades lämna häckningslokalen först omkring 25 september ett år med mycket högt vattenstånd (1995). Vi mätte inte vattenståndet i sjöarna, men genom att okulärt jämföra vattenytans läge med den högsta 
punkten på exponerade boholmar i några av sjöarna, kunde vi göra en kvalitativ, relativ jämförelse mellan åren. I Tabell 2 anges vattenståndet i slutet av juni i en fyra-gradig skala. Den sena vårfloden i skogslandet i kombination med kall väderlek och ovanligt mycket regn i månadsskiftet maj/juni (SMHI 1995) gav ett betydligt högre vattenstånd i sjöarna 1995 jämfört med säsongerna 1993 och 1994. Under säsongerna 1997 och 1998 var vattenståndet lika högt eller t.o.m. högre än under 1995 i slutet av häckningssäsongen (p.g.a. mycken nederbörd under sommaren), men lägre under slutet av juni. Av de sju ruvningar som påbörjades före andra veckan i juni 1995 avbröts samtliga utom en. Utan att ha direkta bevis för dränkta boplatser sätter vi dessa avbrutna häckningar i samband med en kraftig höjning av vattennivån under andra halvan av juni. Under 1995 bytte två av paren initialt den boplats som varit lyckosam under såväl 1993 som 1994 mot en torrare plats belägen på fastare mark. Dessa boplatser var troligen ett andrahandsval då båda paren återvände till den tidigare använda boplatsen när vattnet dragit sig tillbaka i början eller mitten av juli. Vad som hände med äggen från den första kullen är okänt. I tre andra tjärnar väntade lommarna med att häcka tills i början av juli 1995, då vattenståndet sjunkit, medan ett par helt avstod häckning då den under 1993 och 1994 ianspråktagna boplatsen var översvämmad under hela häckningssäsongen. Lommarna låg dock kvar i tjärnen under hela sommaren.

\section{Häckningsresultat}

Häckningsresultaten för åren 1993-1998 redovisas i Tabell 2. Den genomsnittliga ungproduktionen per påbörjad häckning (ruvning) var 0,81 stora ungar ( \pm SD 0,31 per par och år). Detta resultat kan jämföras med en genomsnittlig ungproduktion om 0,67 och 0,88 stora ungar per påbörjad häckning och år för inlandsfiskande smålommar i sydvästra Sverige under perioden 1980-1996 (Eriksson \& Johansson 1997), respektive under perioden 1991-95 i Malungstrakten, Dalarna (Dahlén, 1996). För södra Finland rapporterade Lokki \& Eklöf (1984) 1,15 pulli och/eller juveniler per påbörjad häckning under perioden 1979-1982. För havsfiskande bestånd har Booth (1982) uppgivit en ungproduktion om 0,70 på Orkneyöarna och Gomersall (1986) 0,45 ungar per häckning på Shetlandsöarna under perioden 1918 $1982(\mathrm{n}=1104)$. Med tanke på att 0,45 och 0,67 stora ungar per häckning på Shetlandsöarna respektive i sydvästra Sverige av författarna ovan ansågs vara tillräckligt för att bibehålla det häckande beståndets storlek i dessa områden, finner vi ingen anledning att dra andra slutsatser än att lommarna i Västerbottens kustland för tillfället reproducerar sig tillräckligt för att vidmakthålla sin numerär.

Procentandelen kullar med två stora ungar var hög i vårt material i jämförelse med litteraturdata. I genomsnitt 54\% av de lyckade häckningarna (15 av 28) resulterade i två stora ungar. Detta kan jämföras med 38\% i studierna genomförda i sydvästra Sverige (Eriksson \& Johansson 1997), 38\% i Malungstrakten (Dahlén 1996) och 34\% hos det havsfiskande beståndet på Shetlandsöarna (Okill \& Wanless 1990). Detta indikerar att fisktillgången i Västerbottens kustland, och/eller andra egenskaper i häckningsmiljön, ger goda förutsättningar att föda upp två ungar.

\section{Betydelsen av sjötyp för häckningsresultatet}

Lyckade häckningar genomfördes i alla tre kategorier av sjöar: myrgöl, skogstjärn och mosaikartad sjö (Tabell 3). Av sjöarna i Tabell 1 gjordes inget bofynd i tjärn 10 och 13 under inventeringsperioden, trots närvaro av stationära par. I sjö 2 kunde vi inte, trots idoga försök, finna boet varför denna sjö inte tagits med i den statistiska analysen av häckningsutfallet.

Av 15 häckningsförsök i myrgöl (sjötyp 1) lyckades endast 3 (20\%), medan 14 av 22 (64\%) försök i skogstjärnar (sjötyp 2) och 11 av 16 (69\%) häckningsförsök i mosaikartade sjöar (sjötyp 3) var lyckosamma. Uttryckt som stora ungar per ruvande par och sjötyp (Tabell 3), visade Kruskal-Wallis test att häckningsutfallet signifikant skilde sig åt mellan de tre sjötyperna $\left(\chi^{2}=6.72,0,01<p<0,05\right)$. Dunn's icke-parametriska test för multipla jämförelser visade att häckningsresultatet i myrgöl (0,33 stora ungar per ruvande par och sjö) avvek mest signifikant från resultatet i mosaikartade sjöar $(0,94$ stora ungar, $\mathrm{Q}=$ $2,36,0,05<\mathrm{p}<0,10)$, medan skillnaden gentemot resultatet i skogssjöar (1,09 stora ungar) hade en svagare signifikans $(\mathrm{Q}=2,06,0,10<\mathrm{p}<0,20)$. För att utröna vilka eventuella faktorer som ligger bakom skillnaderna i häckningsresultat mellan sjötyperna nyttjades Spearman's rank korrelation för att relatera häckningsresultatet till (A) häckningssjöarnas geografiska karakteristik och (B) karakteristik kopplad till boplatsens närmiljö.

(A) Betydelsen av häckningssjöns geografi för häckningsresultatet

Korrelationen mellan var och en av faktorerna i Tabell 1 och antalet stora ungar per påbörjad ruvning och sjö (Tabell 4, kolumn 3) redovisas i Tabell 5. Av 
Tabell 1. Fysiska data för 17 sjöar inom undersökningsområdet som uppvisade stationära par åtminstone en gång under perioden 1993-1998. Sjöarna är ordnade enligt fallande total sjöyta. Sjöarna indelas i tre typer: nr 1 dystrof myrgöl, nr 2 oligotrof skogstjärn och nr 3 näringsrik mosaik av sjö, kärr- och mosse-element.

Physical description of 17 lakes within the study area which at least once had a stationary pair during 1993-1998. Lakes are sorted by decreasing lake area. Lakes are divided into three groups: no. 1 a nutrient poor mire lake, no. 2 an oligotrophic forest lake and no. 3 a mosaic of open water, floating vegetation, nutrient demanding higher Scirpus and Carex vegetation and Sphagnum mats.

\begin{tabular}{|c|c|c|c|c|c|c|}
\hline Sjö nr. & $\begin{array}{l}\text { Total } \\
\text { sjöyta, ha }\end{array}$ & $\begin{array}{l}\text { Klar- } \\
\text { vattenyta, ha } \\
\text { (\% klarvatten } \\
\text { av total yta) }\end{array}$ & $\begin{array}{l}\text { Största avstånd } \\
\text { över öppet } \\
\text { vatten, m }\end{array}$ & $\begin{array}{l}\text { Sjöns } \\
\text { ungefärliga } \\
\text { ålder, år }\end{array}$ & $\begin{array}{l}\text { Avstånd till } \\
\text { havsvik eller } \\
\text { kust (avstånd } \\
\text { till } 3 \text { m djup- } \\
\text { kurva), km }\end{array}$ & $\begin{array}{l}\text { Typ av } \\
\text { sjö }\end{array}$ \\
\hline Lake no. & $\begin{array}{l}\text { Total lake } \\
\text { area, ha }\end{array}$ & $\begin{array}{l}\text { Open water } \\
\text { area, ha }(\% \\
\text { open water of } \\
\text { total area })\end{array}$ & $\begin{array}{l}\text { Maximum } \\
\text { distance over } \\
\text { open water, } m\end{array}$ & $\begin{array}{l}\text { Estimated } \\
\text { age of } \\
\text { lake, years }\end{array}$ & $\begin{array}{l}\text { Distance to sea } \\
\text { (distance to } 3 \mathrm{~m} \\
\text { sea depth), } \mathrm{km}\end{array}$ & $\begin{array}{l}\text { Lake } \\
\text { type }\end{array}$ \\
\hline 1 & 15,9 & 2,7 (17) & 210 & 2500 & $4,0(4,3)$ & 3 \\
\hline 2 & 7,7 & 7,4 (96) & 830 & 250 & $0,5(3,0)$ & 2 \\
\hline 3 & 1,7 & $1,4(82)$ & 230 & 250 & $0,3(0,7)$ & 2 \\
\hline 4 & 1,6 & $1,6(100)$ & 300 & 1500 & $0,5(2,0)$ & 2 \\
\hline 5 & 1,4 & $1,4(100)$ & 170 & 1500 & $0,7(2,8)$ & 1 \\
\hline 6 & 1,1 & 0,99 (90) & 180 & 350 & $0,6(3,6)$ & 2 \\
\hline 7 & 1,0 & 0,95 (95) & 230 & 800 & $0,8(1,7)$ & 2 \\
\hline 8 & 0,98 & 0,18 (18) & 100 & 1800 & $2,2(4,7)$ & 3 \\
\hline 9 & 0,88 & 0,58 (66) & 180 & 150 & $0,5(1,5)$ & 2 \\
\hline 10 & 0,81 & 0,81 (100) & 250 & 3500 & $5,4(12,7)$ & 1 \\
\hline 11 & 0,78 & $0,51(65)$ & 60 & 3500 & $3,7(11,5)$ & 3 \\
\hline 12 & 0,75 & 0,75 (100) & 170 & 3500 & $5,5(6,5)$ & 1 \\
\hline 13 & 0,61 & $0,61(100)$ & 170 & 1500 & $1,0(3,9)$ & 1 \\
\hline 14 & 0,40 & 0,17 (42) & 50 & 2500 & $2,6(5,7)$ & 3 \\
\hline 15 & 0,39 & 0,39 (100) & 70 & 2500 & $2,1(2,4)$ & 1 \\
\hline 16 & 0,30 & $0,30(100)$ & 60 & 3500 & $3,3(5,8)$ & 1 \\
\hline 17 & 0,26 & 0,26 (100) & 100 & 1500 & $1,6(3,3)$ & 1 \\
\hline
\end{tabular}

faktorerna i Tabell 1 visade sig endast procentandelen öppen vattenyta ge ett signifikant (negativt) samband med häckningsresultatet (Tabell 5, Spearman's $\left.r_{s}=-0,64, p<0,01\right)$. Detta tolkar vi som att sjöar med relativt ymnig vattenvegetation i form av flytande växter, mer eller mindre flytande vitmossemattor och ruggar av starr och säv, d.v.s. sjöar med en mosaikartad karaktär, ger en för smålommen mer fördelaktig häckningsmiljö än sjöar dominerade av öppet vatten. Sambandet ger således en förklaring till varför de mosaikartade sjöarna uppvisade ett signifikant bättre häckningsutfall än myrtjärnarna under perioden. Av övriga faktorer i Tabell 1 gav även den absoluta arealen klarvattenyta en viss negativ korrelation med häckningsutfallet (Tabell 5). Detta är sannolikt ett uttryck för att sjöar med bety- dande vattenvegetation, snarare än små sjöar med dominerande öppet vatten, är fördelaktiga för smålommen (se nedan).

Att total sjöyta och avstånd från häckningssjö till havet (eller dess $3 \mathrm{~m}$ djupkurva) inte visade någon korrelation med häckningsresultatet (Tabell 5) är inte förvånande i sken av resultat från tidigare studier. Eriksson \& Johansson (1997), som undersökte sjöar av ungefär samma storlek som vi (0,4-33,1 ha), fann inget signifikant samband mellan medelantalet stora ungar per sjö och år och häckningssjöns areal. På Shetlandsöarna har både Okill \& Wanless (1990) och Gomersall (1986) däremot funnit att lommar häckande i sjöar mindre än 0,3 ha respektive 1 ha hade en högre ungproduktion än lommar häckande i större sjöar. Gomersall angav en ökad störning från 
Tabell 2. Vattenstånd i häckningssjöar samt häckningsresultat för åren 1993-1998.

Relative water levels in lakes and reproduction of young 1993-1998.

\begin{tabular}{|c|c|c|c|c|c|c|c|c|c|c|}
\hline Säsong & $\begin{array}{l}\text { Relativt } \\
\text { vattenstånd }\end{array}$ & $\begin{array}{l}\text { (1) } \\
\text { Ruvande } \\
\text { par }\end{array}$ & $\begin{array}{l}(2) \\
\text { Stationära } \\
\text { par }\end{array}$ & $\begin{array}{l}(3) \\
\text { Par } \\
(1)+(2)\end{array}$ & $\begin{array}{l}\text { (4) } \\
\text { Stora } \\
\text { ungar }\end{array}$ & $\begin{array}{l}(5) \\
\text { Lyckade } \\
\text { häckningar } \\
(\% \text { av (1)) }\end{array}$ & $\begin{array}{l}(6) \\
\text { Ruvande } \\
\text { par med } 2 \\
\text { stora ungar } \\
(\% \text { av (1)) }\end{array}$ & $\begin{array}{l}(4) /(1) \\
\text { Stora } \\
\text { ungar / } \\
\text { ruvning }\end{array}$ & $\begin{array}{l}\text { (4) / (3) } \\
\text { Stora } \\
\text { ungar / } \\
\text { par }\end{array}$ & $\begin{array}{l}(4) /(5) \\
\text { Stora } \\
\text { ungar / } \\
\text { lyckad } \\
\text { häckning }\end{array}$ \\
\hline Season & $\begin{array}{l}\text { Relative } \\
\text { water level }\end{array}$ & $\begin{array}{l}\text { Incubating } \\
\text { pairs }\end{array}$ & $\begin{array}{l}\text { Stationary } \\
\text { pairs }\end{array}$ & $\begin{array}{l}\text { Pairs } \\
(1)+(2)\end{array}$ & $\begin{array}{l}\text { Large } \\
\text { young }\end{array}$ & $\begin{array}{l}\text { Successful } \\
\text { breeding } \\
(\% \text { of }(1))\end{array}$ & $\begin{array}{l}\text { Incubating } \\
\text { pairs with } 2 \\
\text { large young } \\
(\% \text { of }(1))\end{array}$ & $\begin{array}{l}\text { Large } \\
\text { young / } \\
\text { incubating } \\
\text { pairs }\end{array}$ & $\begin{array}{l}\text { Large } \\
\text { young / } \\
\text { pairs }\end{array}$ & $\begin{array}{l}\text { Large } \\
\text { young / } \\
\text { successful } \\
\text { breeding }\end{array}$ \\
\hline 1993 & lågt low & 8 & 4 & 12 & 9 & $6(75)$ & $3(38)$ & 1,12 & 0,75 & 1,5 \\
\hline 1994 & $\begin{array}{l}\text { medel } \\
\text { intermediate }\end{array}$ & 12 & 2 & 14 & 12 & $7(58)$ & $5(41)$ & 1,00 & 0,86 & 1,7 \\
\hline 1995 & $\begin{array}{l}\text { mycket högt } \\
\text { very high }\end{array}$ & 11 & 4 & 15 & 6 & $4(36)$ & $2(18)$ & 0,55 & 0,40 & 1,5 \\
\hline 1996 & högt high & 7 & 6 & 13 & 3 & $3(43)$ & $0(0)$ & 0,43 & 0,23 & 1,0 \\
\hline 1997 & högt high & 8 & 5 & 13 & 5 & $3(38)$ & $2(25)$ & 0,62 & 0,33 & 1,7 \\
\hline 1998 & högt high & 7 & $?$ & $?$ & 8 & $5(71)$ & $3(43)$ & 1,14 & $?$ & 1,6 \\
\hline 1993-98 & & 53 & & & 43 & $28(53)$ & $15(28)$ & 0,81 & $0,48^{*}$ & 1,5 \\
\hline
\end{tabular}

* 1993-1997

människan med ökad sjöyta som den troliga förklaringen. Vår bedömning är att det i dagsläget inte finns någon påtaglig mänsklig störning av häckande smålom inom vårt studieområde.

Beträffande närhet mellan häckningstjärn och fiskeplats, konstaterade Eberl \& Picman (1993) att avståndet inte hade någon betydelse för uppfödningen av ungar men att sannolikheten för att kläcka två ägg var signifikant större för par med ett avstånd till fiskeplatsen understigande $9 \mathrm{~km}$. För många studerade populationer har det maximala avståndet till fiskeplatserna legat runt 7-8 km (Douglas \& Reimchen 1988, Eriksson m.fl. 1990, denna studie), varför slutsatser angående effekter av längre flygavstånd inte låtit sig göras. Vi kan alltså anta att vårt material både beträffande sjöareal och avstånd till fiskeplats var för snävt för att ge några signifikanta skillnader mellan sjöar i detta avseende.

(B) Betydelsen av boplatsens närmiljö för häckningsresultatet

Boplatsen och dess närmiljö karakteriseras i Tabell

Tabell 3. Häckningsutfall för de tre olika sjötyperna uttryckt som medelantal stora ungar per ruvning, år och sjö

Reproductive success for Red-Throated Divers in three different types of lakes determined as large young per incubation, year and lake

\begin{tabular}{lll}
\hline Sjötyp & $\begin{array}{l}\text { Antal sjöar } \\
\text { (antal ruvningar) }\end{array}$ & $\begin{array}{l}\text { Medelantal stora ungar per } \\
\text { ruvning 1993-1998 }\end{array}$ \\
Lake type & $\begin{array}{l}\text { Number of lakes } \\
\text { (numbers of incubations) }\end{array}$ & $\begin{array}{l}\text { Mean number of large young } \\
\text { per incubation 1993-1998 }\end{array}$ \\
\hline
\end{tabular}

Myrgöl (sjötyp 1) Mire lake (type 1)

Skogstjärn (sjötyp 2) Forest lake (type 2)

Mosaik myr/sjö Mosaic (type 3)

$4(16)$

0,94 
4 som avståndet mellan boplatsen och sammanhängande gungfly, avståndet mellan boplatsen och fast mark, samt täckningsgraden av högvuxen vegetation $0,5 \mathrm{~m}$ från bobalen.

Av Tabell 4 framgår att 15 av 19 funna boplatser var öar i så måtto att de omgavs av en klarvattenyta under hela häckningssäsongen (avstånd mellan bobale och gungfly större än $0 \mathrm{~m}$ ). Av dessa 15 öar var tre av fastmarkstyp medan 12 var uppbyggda av vitmossemattor och/eller starr och sävruggar. Övriga fyra boplatser var belägna på mer eller mindre gungflyartade vitmossemattor i direkt anslutning till fastmark. Par utnyttjande dessa bon var inte i något enda fall lyckosamma. Inget bo återfanns på ren fastmark.

Betydelsen av bobalens närmiljö för häckningsutfallet utvärderades genom att korrelera var och en av faktorerna i Tabell 4 (kolumn 4-6) med antalet stora ungar producerade per boplats (Tabell 4, kolumn 3). Korrelationskoefficienterna (Spearman's $r_{s}$ ) och deras signifikanser presenteras i Tabell 5. Det framgår av tabellen att täckningsgraden av mer högvuxen

Tabell 4. Häckningsresultat 1993-1998 samt data för boplatsens fysiska tillgänglighet och vegetation i dess omedelbara närhet. Tjärnarna är ordnade i fallande storleksordning.

Reproductive success 1993-1998 and physical data for nesting sites.

\begin{tabular}{|c|c|c|c|c|c|}
\hline $\begin{array}{l}\text { Sjö nr. } \\
\text { och } \\
\text { bobalar } \\
(\text { a,b...) }\end{array}$ & $\begin{array}{l}\text { Antal ruvningar } \\
\text { 1993-1998 } \\
\text { (med lyckat } \\
\text { resultat) }\end{array}$ & $\begin{array}{l}\text { Medelantal } \\
\text { stora ungar per } \\
\text { ruvning, år och } \\
\text { boplats }\end{array}$ & $\begin{array}{l}\text { Avstånd från } \\
\text { boplats till } \\
\text { sammanhängande } \\
\text { gungfly eller } \\
\text { tät veg, m }\end{array}$ & $\begin{array}{l}\text { Avstånd från } \\
\text { boplats till } \\
\text { fast mark, m }\end{array}$ & $\begin{array}{l}\text { Täckningsgrad av } \\
\text { vegetation högre } \\
\text { än } 3 \mathrm{dm} \text { inom } 0.5 \mathrm{~m} \\
\text { från boet, \% }\end{array}$ \\
\hline $\begin{array}{l}\text { Lake no. } \\
\text { and nests } \\
(a, b \ldots)\end{array}$ & $\begin{array}{l}\text { Number of } \\
\text { incubations } \\
\text { 1993-1998 } \\
\text { (successful) }\end{array}$ & $\begin{array}{l}\text { Large young } \\
\text { per incubation, } \\
\text { year and nest }\end{array}$ & $\begin{array}{l}\text { Distance } \\
\text { between nest } \\
\text { and floating } \\
\text { vegetation, } m\end{array}$ & $\begin{array}{l}\text { Distance } \\
\text { between nest } \\
\text { and solid } \\
\text { ground, } m\end{array}$ & $\begin{array}{l}\text { Coverage by } \\
\text { vegetation above } \\
3 \text { dm heigh within } \\
0.5 \text { m from nest, } \%\end{array}$ \\
\hline $1 \mathrm{a}$ & $3(2)$ & 0,67 & $>10$ & $>30$ & 50 \\
\hline $1 b$ & $2(0)$ & 0,00 & $>10$ & $>30$ & 50 \\
\hline $1 \mathrm{c}$ & $\begin{array}{l}1(0) \\
1 a+1 b+1 c: 6(2)\end{array}$ & $\begin{array}{l}0,00 \\
1 a+1 b+1 c: 0,33\end{array}$ & $>10$ & $>30$ & 50 \\
\hline 2 & $?(2)$ & 2,00 & \multicolumn{3}{|c|}{ bobalen ej lokaliserad nest not located } \\
\hline $3 \mathrm{a}$ & $2(1)$ & 0,50 & 45 & 45 & 20 \\
\hline $3 b$ & $\begin{array}{l}2(1) \\
3 a+3 b: 4(2)\end{array}$ & $\begin{array}{l}1,00 \\
3 a+3 b: 0,75\end{array}$ & 10 & 10 & 50 \\
\hline 4 & $2(1)$ & 0,50 & 1,0 & 3 & $20-30$ \\
\hline 5 & $2(0)$ & 0,00 & 0 & 3 & $<20$ \\
\hline $6 a$ & $3(2)$ & 1,33 & 10 & 10 & 50 \\
\hline $6 b$ & $\begin{array}{l}2(1) \\
6 a+6 b: 5(3)\end{array}$ & $\begin{array}{l}1,00 \\
6 a+6 b: 1,20\end{array}$ & 0 & 20 & 60 \\
\hline 7 & $4(3)$ & 1,00 & 2,5 & 10 & $10-30$ \\
\hline 8 & $3(3)$ & 1,67 & $>10$ & $>30$ & 50 \\
\hline 9 & $5(3)$ & 1,00 & 8 & 8 & 50 \\
\hline 11 & $4(3)$ & 1,00 & $>10$ & $>30$ & 50 \\
\hline 12 & $1(0)$ & 0,00 & 0 & 3 & $<10$ \\
\hline 14 & $3(3)$ & 1,33 & 0,5 & 25 & $70-80$ \\
\hline 15 & $3(1)$ & 0,67 & 1,0 & 3 & $<10$ \\
\hline $16 \mathrm{a}$ & $4(2)$ & 0,75 & 4 & 4 & $20-30$ \\
\hline $16 b$ & $\begin{array}{l}2(0) \\
16 a+16 b: 6(2)\end{array}$ & $\begin{array}{l}0,00 \\
16 a+16 b: 0,50\end{array}$ & 0 & 3 & $10-30$ \\
\hline 17 & $3(0)$ & 0,00 & 0 & 1,0 & $<10$ \\
\hline
\end{tabular}


(>3 dm) vegetation visade den starkaste samvariationen med häckningsresultatet, medan avståndet mellan boplats och sammanhängande gungfly, eller mellan boplats och fastmark, gav svagare samband. Resultatet indikerar, givet att boet är beläget på en ö av fastmarks- eller gungflykaraktär, att ett gott insynsskydd i form av tät högvuxen vegetation är viktigare för ett lyckat häckningsresultat än det absoluta avståndet till land eller gungflyvegetation.

Orsaken till att vegetationsrika sjöar ger ett bättre häckningsresultat än vegetationsfattiga sjöar är sannolikt att de förra sjöarna, $i$ typfallet, medger fler och bättre skyddade boplatser. Det är känt från tidigare studier att nyttjandet av en mindre holme som boplats är mycket fördelaktigt i miljöer med landpre- datorer (Lokki \& Eklöf 1984, Eberl \& Picman 1993, Eriksson \& Johansson 1997). På Shetlandsöarna, vilka i huvudsak saknar landpredatorer, fann Gomersall (1986) inte någon signifikant skillnad i häckningsresultat mellan häckning på holme och på stranden. Betydelsen av en skyddande, högvuxen vegetation har däremot, enligt vår kännedom, inte visats eller poängterats i tidigare studier.

\section{Predation och störningar}

Intressant att notera är att antalet stora ungar per lyckad häckning inte skiljer sig mellan åren, medan antalet stora ungar per påbörjad häckning varierar kraftigt (Tabell 2). Detta tyder på att häckningsresul-

Tabell 5. Statistisk utvärdering av sjö- och boplatsegenskapers inverkan på häckningsutfallet

Statistical evaluation of the influence of lake and nesting site characteristics on breeding result

\begin{tabular}{|c|c|c|c|}
\hline $\begin{array}{l}\text { Sjö (I-VI) eller boplatsegenskap } \\
(1-3) \\
\text { Lake (I-VII) and nesting place } \\
\text { characteristics (1-3) }\end{array}$ & $\begin{array}{l}\text { Antal sjöar }(\mathrm{n}=14) \text { eller } \\
\text { boplatser }(\mathrm{n}=19) \\
\text { Number of lakes }(n=14) \text { or } \\
\text { number of nesting sites } \\
(n=19)\end{array}$ & $\begin{array}{l}\text { Spearmans } \\
\text { korrelations- } \\
\text { koefficient } r_{s} \\
\text { Spearman's } \\
\text { correlation } \\
\text { coefficient } r_{s}\end{array}$ & $\begin{array}{l}\text { Statistisk } \\
\text { signifikans } \\
\text { Statistical } \\
\text { significance }\end{array}$ \\
\hline $\begin{array}{l}\text { I. Total sjöyta } \\
\text { Total lake area }\end{array}$ & 14 & $+0,04$ & NS \\
\hline $\begin{array}{l}\text { II. Klarvattenyta } \\
\text { Open water area }\end{array}$ & 14 & $-0,38$ & $0,05<\mathrm{p}<0,10$ \\
\hline $\begin{array}{l}\text { III. \% klarvattenyta } \\
\text { \% open water }\end{array}$ & 14 & $-0,64$ & $\mathrm{p}<0,01$ \\
\hline $\begin{array}{l}\text { IV. Minsta avstånd över öppet vatten } \\
\text { Minimum distance over open water }\end{array}$ & 14 & $-0,16$ & NS \\
\hline $\begin{array}{l}\text { V. Sjöns ungefärliga ålder } \\
\text { Age of lake }\end{array}$ & 14 & $-0,22$ & $0,10<\mathrm{p}<0,25$ \\
\hline $\begin{array}{l}\text { VI. Avstånd häckningssjö - kustlinje } \\
\text { Distance between lake and sea } \\
\text { VII. Avstånd häckningssjö - } 3 \mathrm{~m} \\
\text { djup-kurva Distance between lake } \\
\text { and } 3 \mathrm{~m} \text { sea depth }\end{array}$ & 14 & $-0,16$ & NS \\
\hline $\begin{array}{l}\text { 1. Avstånd boplats - gungfly / } \\
\text { tät vegetation Distance between } \\
\text { nest and floating vegetation }\end{array}$ & 19 & $+0,36$ & $0,05<\mathrm{p}<0,10$ \\
\hline $\begin{array}{l}\text { 2. Avstånd boplats - fast mark } \\
\text { Distance between nest and solid } \\
\text { ground }\end{array}$ & 19 & $+0,36$ & $0,05<\mathrm{p}<0,10$ \\
\hline $\begin{array}{l}\text { 3. Täckningsgrad av vegetation } \\
\text { högre än } 3 \mathrm{dm} \text { inom } 0,5 \mathrm{~m} \text { från boet } \\
\text { Coverage of vegetation higher than } \\
3 \text { dm within } 0,5 \mathrm{~m} \text { from nest }\end{array}$ & 19 & $+0,65$ & $\mathrm{p}<0,01$ \\
\hline
\end{tabular}


tatet till största delen påverkas av faktorer som gör sig gällande innan ungarna lämnar redet, d.v.s. under ruvningstid och just då ungarna kläckts.

$\mathrm{Vi}$ gjorde inte någon direkt observation av boplundring eller rov av unge i vår studie. Om vi utgår från att alla ruvande fåglar lagt två ägg (Eberl \& Picman 1993), så skulle 67 av totalt 110 lagda ägg (inklusive två omläggningar 1995) i vår studie ha resulterat i förluster. Eftersom endast en unge med säkerhet kunde konstateras försvinna, innebär det att 66 (98\%) av förlusterna under 1993-1998 var i form av ägg eller i det närmaste nykläckta ungar.

Det har i tidigare studier visat sig vara mycket svårt att definitivt säkerställa orsaker bakom avbrutna häckningar, eftersom det i stort sett kräver ständig bevakning. Under studier av 73 smålomspar 1981 och 64 par 1982 på Shetlandsöarna (Gomersall 1986) kunde orsakerna till förluster av ägg eller ungar endast fastställas i 4 av 332 fall $(1,2 \%)$ genom direkt observation av boplundring. Indirekt gavs indikationer om 15 fall (4\%) av översvämning av boet under ruvning, 174 fall (52\%) av plundrade ägg, 90 fall $(27 \%)$ av rövade ungar och 53 fall (15\%) av förluster i form av försvunna ägg eller ungar. Eberl \& Picman (1989) fann under det första året i sin studie av kustfiskande smålommar i Alaska att avsaknad av förluster av ägg sammanföll med frånvaro av predatorer. Av nio förluster i form av ungar var åtta ungar mindre än en vecka gamla då de försvann. Det andra året var predationen betydligt högre och $43 \%$ av lommarna misslyckades med att få ut ungar. Hela $80 \%$ av förlusterna tillskrevs detta år försvunna ägg. Bundy (1976) anger att förluster av stora ungar är förhållandevis ovanligt.

Trots svårigheten att särskilja predation av ägg och nykläckta ungar så indikerar dessa resultat sammantaget att predation av ägg och/eller kraftiga störningar som leder till övergivande av boplatsen under ruvningstid sannolikt är den mest avgörande faktorn för häckningsresultatet under år med normalt vattenstånd. Betydelsen av översvämning för häckningsresultatet kan endast utvärderas med hjälp av längre tidsserier eftersom variationerna mellan åren är stora.

Vilka är då möjliga rövare av ägg eller ungar i vårt studieområde? Attack från duvhök Accipiter gentilis direkt mot ruvande fågel iakttogs vid två tillfällen och mot en store unge vid ett tillfälle. I båda fallen utan lycka för höken. Däremot sågs havsörn Haliaeetus albicilla skrämma den ruvande fågeln av boet i tjärn 4 nära den tidpunkt då boet övergavs. Övriga möjliga predatorer är framförallt räv Vulpes vulpes och mink Mustela vison. Av fåglar bör kråka Corvus corone och korp Corvus corax utgöra potentiella predatorer, framförallt i samband med annan (mänsklig) störning. Vi noterade dock varken direkta eller indirekta störningar eller störningsrisker från människor. Gädda Esox lusius är en möjlig predator av små ungar i de större sjöarna.

\section{Inverkan av dikning på häckningstjärnarna}

Utan att närmare studier gjorts har några av häckningssjöarna i föreliggande studie sannolikt blivit mer gynnsamma för smålommen efter dikningsingrepp. I dessa fall har vattenståndet höjts genom en ökad tillrinning från dikade områden uppströms. Konsekvensen har varit en eutrofiering resulterande i en ökad mosaik av högstarrbälten och gungflymattor. Alternativa häckplatser har skapats samtidigt som det funnits tillräcklig yta av öppna vattenspeglar. Detta är intressant i perspektivet att en ökad eutrofiering och igenväxning p.g.a. dikning sannolikt varit en orsak tillbakagången av smålomsbeståndet i sydvästra Sverige under perioden 19351987 (Eriksson m.fl. 1988). I dessa fall har dikningen lett till en torrläggning av häckningssjöar. Huruvida torrlagda dikningsobjekt inom vårt studieområde tidigare hyst häckande smålom är för oss okänt.

\section{Tack}

Vi tackar Mats O. G. Eriksson för värdefulla synpunkter på manus. Medel för denna studie har medgivits av Alvins Fond förvaltad av Svenska Naturskyddsföreningen, Elis Wides Fond förvaltad av Sveriges Ornitologiska Förening samt av Västerbottens Ornitologiska Förenings fågelskyddsfond. Vi tackar för detta stöd.

\section{Referenser}

Booth, C. J. 1982. Fledging success of some red-throated divers in Orkney. Scottish Birds 12: 33-38.

Bundy, G. 1976. Breeding biology of the red-throated diver. Bird study 23: 249-256.

Dahlén, B. 1996. Inventering av smålom i Malungs socken 1995. Fåglar i Dalarna 29: 3-11.

Douglas, S. D. \& Reimchen, T. E. 1988. Habitat characteristics and population estimate of breeding Red-Throated Loons, Gavia stellata, on the Queen Charlotte Islands, British Columbia. Canadian Field-Naturlist 102: 679-684.

Eberl, C. \& Picman, J. 1993. Effect of nest-site location on reproductive success of Red-Throated Loon (Gavia stellata). Auk 110(3): 436-444.

Eriksson, M. O. G. 1987. Smålommens val av häckningstjär- 
nar och fiskesjöar; några preliminära resultat från en undersökning i södra Älvsborgs län. Gavia 13: 50-59.

Eriksson, M. O. G. 1994. Susceptibility to freshwater acidification by two species of loon: Red-throated loon Gavia stellata and Arctic loon Gavia arctica in south-west Sweden. Hydrobiologia 279/280: 439-444.

Eriksson, M. O. G., Arvidsson, B. L. \& Johansson, I. 1988. Habitatkaraktärer hos häckningssjöar för smålom Gavia stellata i sydvästra Sverige. Vår Fågelvärld 47: 122-132.

Eriksson, M.O.G. \& Johansson, I. 1997. Smålommen Gavia stellata i sydvästra Sverige - beståndsutveckling och häckningsframgång. Ornis Svecica 7: 1-10.

Eriksson, M. O. G. \& Lindberg, P. 1999. Projekt lom inventeringsrapport 1998. Svenska naturskyddsföreningen, Stockholm.

Gomersall, C. H. 1986. Breeding performance of the redthroated diver Gavia stellata in Shetland. Holarctic Ecology 9: 277-284.

Lokki, J. \& Eklöf, K. 1984. Breeding success of the RedThroated Diver Gavia stellata in southern Finland. Annales Zoologia Fennici 21: 417-419.

Okill, J.D. \& Wanless, S. 1990. Breeding success and chick growth of Red-Throated Diver Gavia stellata in Shetland 1979-1988. Ringing \& Migration 10: 26-30.

Olsson, C. 1992. Inventering av Umeå kommuns sjöar. Fåglar $i$ Västerbotten 17: 86-116.

Sjörs, H. 1956. Nordisk växtgeografi. Almqvist och Wiksell.

SMHI, 1995. Väder och vatten - Juni 1995. Sveriges meteorologiska och hydrologiska institut, Norrköping.

\section{Summary}

Importance of lake and nesting site characteristics for the breeding success of sea-foraging Red-throated Divers Gavia stellata in Västerbotten, Sweden

In contrast to the world population, the majority of the estimated 1200-1400 pairs of Red-Throated Divers breeding in Sweden (Eriksson \& Lindberg 1999) forage in fresh water lakes. Only in north-eastern Sweden, along the Bothian Bay and Gulf of Bothnia, there is a small population of sea-foraging Red-Throated Divers. The biology and breeding success of these birds are basically unknown. Therefore, approximately 15 pairs were studied during the period 1993-1998 within an area of about $400 \mathrm{~km}^{2}$ (Figure 1). In addition to determine the breeding success, the geography and vegetation of breeding lakes and the nesting site environment were characterised.

\section{Material and methods}

Topography, geology and vegetation

The study area is characterised by a north-south oriented relief formed by the deposition of glacial till during the last ice age. Lakes close to the coast ( 0 $2 \mathrm{~km}$ ) are often found in the depressions between ridges, whereas mire lakes formed in the centres of more extensive peatlands are more common further inland. Seventeen of the 135 lakes within the 400 $\mathrm{km}^{2}$ study area are presented in Table 1. Fourteen of these hosted breeding pairs and three hosted nonbreeding, stationary pairs, at least once during the study period 1993-1998.

The geology is dominated by nutrient-poor gneiss, and therefore lakes and peatlands are of fairly nutrient-poor types. Plants such as Andromeda polifolia, Vaccinium oxycoccus, Ledum palustre and Calluna vulgaris predominates on mires, whereas the shore of nutrient-poor lakes are characterised by Eriophorum vaginatum, Carex limosa, C. curta, Comarum palustre and Menyanthes trifoliata. The more nutrient-rich lakes of the area show patches of highgrown Carex rostrata, C. lasiocarpa and Equisetum fluviatile. Norway spruce Picea abies forests cover most of the area and Scots pine Pinus sylvestris is found sparsely on mires and in the transition between mires and well-drained uplands. Young Scots pine plantations are found surrounding some lakes. The deciduous trees Betula pubescens, Sorbus aucuparia and Alnus incana locally dominate around breeding lakes.

\section{Classification of lakes}

The breeding lakes were categorised into three types: (1) Nutrient poor mire lakes have a water column which is more or less isolated from minerotrophic water by extensive Spaghnum peatland. In the typical case the shore have a rounded contour, shaped by Sphagnum mosses, only sparsely vegetated with low-growing Carex vegetation. In some cases a narrow zone of slightly higher vegetation is found close to the water edge (Figure 2). (2) Oligotrophic forest lakes (Figure 3a) are formed in depressions of the glacial till and its shoreline only partly is covered by Sphagnum peat. These lakes receive minerogenic groundwater and are more nutrient-rich than mire lakes. The extension of patches of higher Carex and Scirpus vegetation varies between lakes and is in the typical case much more pronounced than in mire lakes (Figure 3b). (3) Mesotrophic lakes have a mosaic character of open water mixed with extensive patches of nutrient demanding higher vegetation, floating vegetation and more or less floating Sphagnum mats. In several cases these lakes are products of up-stream forest ditching, leading to an input of water and nutrients to the lakes (Figure 4). 
A number of physical parameters were measured for each breeding lake (Table 1). The lake area was measured from maps, whereas the area of open water was measured from photographs taken from aeroplane during summer 1990. The age of the lake was calculated from altitude above sea level and an estimated land rise of $0.9 \mathrm{~m}$ per 100 years within the area. The distance between breeding lake and the sea was measured on the topographic map.

\section{Inventory methods}

On average each lake was visited four or five times from the end of May to September each year. Pairs found in a lake at least twice during May - June, but not showing any signs of breeding, were designated stationary pairs. All lakes with stationary pairs, as well as lakes with single divers were checked at least twice for incubation until the end of July. The criterion for a breeding pair was observation of incubating birds. Incubating pairs were checked once or twice in July for newly hatched chicks and once or twice in August for a control of large young. Large young were defined as being at least half the size of the parents. Fledged youngsters were not checked specifically. After the young had left the lakes, the distance between the nest and the nearest solid ground (shore) and the distance between the nest and the nearest continuous floating vegetation mat were measured. The coverage of vegetation higher than $0.3 \mathrm{~m}$ within $0.5 \mathrm{~m}$ from the nest, was also measured.

\section{Results and discussion}

\section{Breeding season and water levels in lakes}

Red-Throated Divers were observed in breeding lakes between the second week of May to the end of September. The estimated date of egg laying varied between 20 May and 10 July. This variation was most likely caused by fluctuations of the water levels in the lakes.

The water level was determined in a relative scale by an ocular comparison of the water table and the surface of small islets used by the divers (Table 2). Based on the approximate date of hatching and a mean time of 45 days for the young to be fledged (Bundy 1976), the breeding season, defined as the time adults or young spent in the lakes, was from 10 May to 30 August a year with an intermediate water level (e.g. 1994), and from 10 May to 25 September a year with very high water level (1995).

\section{Reproductive success}

During the years 1993-1998, a total of 53 initiated incubations were recorded in 14 lakes. The average production was $0.81( \pm$ SD 0.31$)$ large young per incubating pair and year. This result can be compared with a production of 0.67 large young in south-west Sweden during 1980-1996 (Eriksson \& Johansson 1997) and 0.88 for large young in central Sweden (Malung) during 1991-1995 (Dahlén 1996). In southern Finland, Lokki \& Eklöf (1984) reported 1.15 young per incubating pairs 1979-1982. All these divers fish in inland waters. Sea-foraging divers in Shetland had a production of 0.45 fledged young in the period 1918-1982 (Gomersall 1986), which was enough to maintain the population size.

The percentage of broods with two large young was high in our material, as compared to literature data. On average, $54 \%$ of the successful breedings (15 of 28) resulted in two large young. This can be compared with $38 \%$ in south-western Sweden (Eriksson \& Johansson 1997), 38\% in central Sweden (Dahlén 1996) and 34\% for a sea-foraging population in Shetland (Okill \& Wanless 1990). This indicates that the conditions for raising chicks might be unusually beneficial in our study area.

\section{Importance of lake type}

Although Red-Throated Divers managed to raise young in all three types of lakes the production was lower in mire lakes (type 1) than in forest lakes (type 2 ) and lakes with a mosaic character (type 3). Out of 15 breeding attempts in mire lakes only three (20\%) were successful, whereas 14 out of $22(64 \%)$ and 11 out of $16(69 \%)$ were successful in forest lakes and mosaic lakes, respectively. Kruskal-Wallis test $\left(\chi^{2}=\right.$ $6.72,0.01<\mathrm{p}<0.05)$ followed by Dunn's test for multiple comparisons showed that the breeding success in mire lakes of 0.33 young per initiated incubation was significantly lower than in mosaic lakes (0.94 young, $\mathrm{Q}=2.36,0.05<\mathrm{p}<0.10)$, whereas the significance was less for the comparison with forest lakes (1.09 young, $\mathrm{Q}=2.06,0.10<\mathrm{p}<0.20$ ). In order to further investigate the factors behind differences in breeding success, the productivity was correlated to (A) lake characteristics and (B) nesting site characteristics.

A) Importance of physical characters of lakes Spearman's rank correlations between each of the geographic characters listed in Table 1, and the 
average of large young per incubation and lake (Table 4, column 3) are presented in Table 5. Only the percentage of open water showed a significant (negative) relation to the breeding result (Spearman's $\mathrm{rs}=-0,64, \mathrm{p}<0,01)$. This indicates that lakes with patches of a relatively dense vegetation, such as high-grown Carex and Scirpus, floating vegetation and more or less floating Sphagnum spp. mats, are more favourable as breeding lakes than lakes with less vegetation and more of open water. The total lake area was not found to be important for the breeding success (Table 5).

The distance between the breeding lakes and the sea was not an important factor (Table 5), which can be explained by the generally very short distances in our material $(0.3-5.4 \mathrm{~km})$. According to Eberl \& Picman (1993) a threshold is found at approximately $9 \mathrm{~km}$, beyond which the possibility to hatch two chicks seemed to decrease.

B) Importance of nesting site characteristics In Table 4 the distance between the nesting site and continuous, floating Sphagnum moss mats, the distance between the nesting site and more solid ground and the percentage coverage of high-grown $(>0.3 \mathrm{~m})$ vegetation within $0.5 \mathrm{~m}$ of the nest are given.

Fifteen of 19 nests were surrounded by water throughout the breeding season. Thus, they were situated on islands. Twelve of these 15 islands were built up by floating Sphagnum mats, more or less mixed with patches of Carex and Scirpus vegetation. The remaining four nests were placed on more or less floating Sphagnum mats in direct connection to the solid shore. None of the divers using these nests were successful. Not a single nest was found on the solid shore.

Spearman's rank correlations were used to relate the influence of each of the factors in column 4-6 in Table 4 to the production of large young per nesting site and lake (Table 4, column 3). The results are shown in Table 5. The coverage of vegetation higher than $0.3 \mathrm{~m}$ within $0.5 \mathrm{~m}$ from the nest was the most important factor for a successful breeding result (Spearman's rs $=0.65, \mathrm{p}<0.01$ ). Given that the nest is situated on an islet, the result indicates that a dense, sheltering vegetation is more important than the absolute distance to the shore. According to our knowledge, this finding is something new.

\section{Predators}

A feasible explanation for the positive effect of dense vegetation close to the nest is a decrease in susceptibility to predation from both the air (birds) and land. Assuming that all incubations resulted in two eggs (cf. Eberl \& Picman 1993), a total of 110 eggs were laid by the divers in our study (including two secondary clutches). Since only one chick was observed to be lost this means that 66 of 67 losses were losses of eggs. Even if it is assumed that we missed some losses of newly hatched chicks, this indicates that most failures took place during incubation. In 1995, undoubtedly flooding of nests resulted in losses of eggs, during the other years disturbances and predation most probably caused most losses. Non-successful attacks of adults on nests by raptors such as Accipiter gentilis and Haliaeetus albicilla were noted. Other possible predators from the air are Corvus corone and Corvus corax. The most probable land predators are Vulpes vulpes and Mustela vison. Also Esox lusius is a possible predator in the larger lakes. 